\title{
NEUROERGONOMIA, NEUROARQUITETURA E AMBIENTE CONSTRUÍDO - TENDENCIA FUTURA OU PRESENTE?
}

\section{NEUROERGONOMICS, NEUROARCHITECTURE AND BUILT ENVIRONMENT - FUTURE TRENDS OR PRESENT?}

\author{
Vilma Villarouco ${ }^{1}$, Dr.Eng. \\ vvillarouco@gmail.com e http://orcid.org/0000-0002-4520-3683 \\ Zilsa Santiago ${ }^{2}$, D.Sc. \\ zilsa@arquitetura.ufc.br e http://orcid.org/0000-0001-9980-04954 \\ Marie Monique de Paiva ${ }^{1}$, D.Sc. \\ mariem.paiva@gmail.com e https://orcid.org/0000-0001-5127-8916 \\ Paulo Nascimento ${ }^{3}$, M.Sc. \\ pauloneurofeedback@gmail.com \\ Raquel Medeiros ${ }^{2}$, Graduanda em Arquitetura e Urbanismo \\ raquelmedeiros@arquitetura.ufc.br
}

\author{
${ }^{1}$ Laboratório de Ergonomia Aplicada ao Ambiente Construído /CAC, UFPE, Recife-PE, Brasil \\ ${ }^{2}$ Laboratório de Ergonomia Aplicada ao Ambiente Construído /PPGAUD - DAUD, UFC, Fortaleza-CE, Brasil \\ ${ }^{3}$ Instituto Le Santè, Fortaleza-CE, Brasil
}

neuroergonomia, neuroarquitetura, acessibilidade urbana, ambiente construído Uma forte convergência para os estudos da neurociência é registrada nos últimos anos em várias áreas do conhecimento. Neste cenário, as pesquisas aqui tratadas estão centradas na aplicação da neurociência em estudos de atividades humanas (neuroergonomia), desenvolvidas no interior de ambientes construídos que despertam sensações e emoções em seus usuários (neuroarquitetura), preocupados também com a inclusão de pessoas com deficiência no uso de espaços (neuroacessibilidade). O objetivo é identificar a adequação de forte conjugação de ferramentas e a sua pertinência nesta linha de abordagem ergonômica. Como resultados, entende-se a associação da utilização da técnica de Eletroencefalografia à Realidade Virtual em espaços residenciais com usuários idosos como elemento inovador e com potencial para as investigações do ambiente construído do ponto de vista ergonômico. Na condução da pesquisa de trajetos urbanos por pessoas cegas com auxílio de Tecnologias Assistivas, os resultados das gravações de EEG apontam ativações de áreas cerebrais por ondas que indicam reações de tranquilidade, atenção e ansiedade, perfeitamente associáveis ao momentos e situações vivenciadas. Embora contando com poucos resultados, os trabalhos indicam a abertura de um leque de possibilidades de novas pesquisas com caráter de ineditismo de alta relevância.

neuroergonomics, neuroarchitecture, urban accessibility, built environment A strong convergence for neuroscience studies is recorded in recent years in various areas of knowledge. In this scenario, the research treated here is focused on the application of neuroscience in human activity studies (neuroergonomics), developed within constructed environments that awaken sensations and emotions in their users (neuroarchitecture), also concerned with the inclusion of people with disabilities in the use of spaces neuroaccessibility). The objective is to identify the adequacy of strong combination of tools and their pertinence in this line of ergonomic approach. As results, we understand the association of the use of the Electroencephalography technique with Virtual Reality in residential spaces with elderly users as an innovative element and with potential for investigations of the environment constructed from the ergonomic point of view. In conducting the research of urban paths by blind people with the help of Assistive Technologies, the results of EEG recordings indicate activations of brain areas by waves that indicate reactions of tranquility, attention and anxiety, perfectly associative to the moments and situations experienced. Although with few results, the studies indicate the opening of a range of possibilities for further research with a character of high-relevance novelty.

DOI: http://dx.doi.org/10.22570/ergodesignhci.v8i2.1459 


\section{Introdução}

Nos anos recentes tem sido registrado um forte crescimento das pesquisas da neurociência aplicada a diversos ramos do conhecimento. Segundo o Brasilian Institute of Neuroscience and Neurotecnology (BRAINN), "em apenas algumas décadas, a humanidade passou da simples análise sob o microscópio de Santiago ${ }^{1}$ para a observação de neurônios humanos em funcionamento em tempo real". Uma forte convergência para os estudos da neurociência é registrada, uma vez que esta viabiliza o entendimento e exploração de sensações de satisfação ou de repúdio, expressas por sinapses encefálicas identificadas a partir de técnicas e equipamentos já consagrados neste ramo aplicados no âmbito da saúde propiciando um vasto leque de possibilidades para a inserção de usuários como provedores de atributos desejados em artefatos, ambientes e situações diversas da vida humana.

Não divergindo de outras áreas como a educação, o marketing, a administração, dentre outras e, formando uma onda crescente, são localizados os estudos da ergonomia e da arquitetura inserindo os conceitos da neurociência, quando a preocupação com o bem estar do ser humano desenvolvendo atividades nos seus ambientes representa o foco principal dessas matérias. Nesses casos, o interesse repousa no entendimento das reações registradas no cérebro a partir de ativações de regiões que representam sentimentos e sensações frente a situações que se deseja pesquisar.

Vasquez et al. (2016) ponderam que, sendo a neuroergonomia entendida como o estudo do cérebro humano e sua relação com o desempenho no trabalho e nas atividades cotidianas, ocupa-se do estudo da estrutura e função do cérebro além das tarefas básicas usadas pela psicologia cognitiva e a neurociência. Nessa direção, os autores concluem que a ergonomia foi se transformando de uma disciplina que visava melhorar a eficiência no trabalho para uma que objetiva melhorar o bem-estar das pessoas.

Direcionando o foco para as questões dos espaços e ambientes construídos, De Paiva (2018) argumenta que os arquitetos sempre souberam o poder de seus edifícios e como eles podem impactar os usuários. A autora coloca que o comportamento também é influenciado pela arquitetura e que essa relação entre meio ambiente e o indivíduo acontece não apenas de forma cognitiva, mas também de uma forma emocional ou mesmo instintiva. Para ela, a neurociência aplicada à arquitetura prova que os espaços podem impactar diretamente na forma como o sistema inconsciente é impactado, não sendo sequer reconhecido em um nível consciente por significativa parte do impacto.

Inseridas nesse cenário, as pesquisas tratadas neste artigo estão centradas na aplicação da neurociência para o aprofundamento dos estudos de atividades humanas (neuroergonomia), desenvolvidas no interior de ambientes construídos que despertam sensações e emoções em seus usuários (neuroarquitetura), preocupados também com a inclusão de pessoas com deficiência no uso de espaços (neuroacessibilidade).

Visando criar experiências diversificadas de aplicação dos conceitos e ferramentas da neurociência, o grupo onde estas pesquisas tem se desenvolvido trabalha na adoção de mesclagem de técnicas e elementos, na busca da formatação de metodologias que atendam às necessidades dos estudos que tem desenvolvido.

Neste sentido, os trabalhos que aqui se apresentam, pertinentes aos domínios da ergonomia aplicada aos ambientes construídos, contemplam a inserção da neurociência na condução das pesquisas. O objetivo é identificar a adequação de uma forte conjugação de ferramentas e a sua pertinência nesta linha de abordagem ergonômica.

\footnotetext{
${ }^{1} \mathrm{O}$ cientista espanhol Santiago Ramón y Cajal conseguiu corar neurônios individuais e descobrir padrões celulares nunca antes percebidos, abrindo caminho para estudos iniciais das células e estruturas que permitem que o cérebro funcione corretamente. Iniciando o ramo da ciência que busca desvendar os quebra-cabeças por trás do poder cerebral: a neurociência. In: www.brainn.org.br
} 
Dos trabalhos recentes desenvolvidos pelo grupo dois são aqui tratados: um centrado na avaliação de ambientes residenciais de pessoas idosas e, outro, nos estudos da acessibilidade urbana focando as pessoas com deficiência visual. Quando se tratou de ambientes para idosos conjugou-se a Seleção Visual à Realidade Virtual com visualização 3D imersiva, mediados pela avaliação da eletroencefalografia. Já para os estudos da acessibilidade com pessoas cegas adotou-se as técnicas de verbalização de rotas e a tecnologia assistiva dos mapas táteis, ambos adotando o foco da neurociência através da avaliação das reações encefálicas pelo uso da eletroencefalografia. $\mathrm{O}$ detalhamento metodológico de cada uma dessas experiências está apresentado no tópico do desenho das pesquisas.

\section{Ergonomia do Ambiente, Neuroergonomia e Neuroarquitetura}

Tanto a neurociência quanto a ergonomia - disciplinas representantes da neuroergonomia - possuem suas constituições formais no século XX. A partir de então, o impressionante desenvolvimento apresentado pela neurociência desde seu surgimento na década de 50, assim como o progresso gradual e constante, mas não menos importante, da ergonomia podem ser atribuídos a um grande avanço tecnológico deste período, especialmente a partir do surgimento dos computadores (WILSON, 2000).

Paradoxalmente a este recente incremento, insere-se aqui a citação de Hipócrates (séc. IX a.C.) apud Bear et al. $(2002$, p.3):
O homem deve saber que de nenhum outro lugar, mas do encéfalo, vem a alegria, o prazer, o riso e a diversão, o pesar, o ressentimento, o desânimo e a lamentação. E por isto, de uma maneira especial, adquirimos sabedoria e conhecimento, e enxergamos e ouvimos e sabemos o que é justo e injusto, o que é bom e o que é ruim, o que é doce e o que é amargo.... E pelo mesmo órgão tornamo-nos loucos e delirantes, e medos e terrores nos assombram.... Todas estas coisas suportamos do encéfalo quando não está sadio.... Neste sentido sou da opinião de que o encéfalo exerce o maior poder sobre o homem.

As diversas áreas do conhecimento se associam à neurociência para tentar desvendar este poder do qual Hipócrates dissertava há mais de dois mil anos. Como esta influência acontece? Como este complexo órgão recebe e processa os estímulos exteriores, associa-os às memórias e vivências e transmite-os ao corpo em forma de sensações? Como esta fonte de informações e experiências pode ser explorada em favor do corpo onde ela se insere?

De fato o tema é complexo e neurocientistas de todas as linhas se esforçam para estabelecer as verdades a respeito do sistema nervoso, considerando a ainda recente criação deste ramo cientifico. A Sociedade de Neurociências foi fundada em 1970, mesmo que se considere que o estudo do encéfalo é tão antigo como a própria ciência (BEAR et al., 2002). Foi o caráter interdisciplinar e a combinação de abordagens que trouxeram grande impulso a estes estudos. Compreender como o encéfalo funciona é a busca do entendimento do ser humano.

É neste contexto que a ergonomia com seu foco principal no humano, encontra nos estudos neurocientíficos uma possibilidade de parceria para adequação de situações diversas de desenvolvimento de atividades. A partir do encontro de diferentes disciplinas, da psicologia cognitiva, neurociência e ergonomia, surge a neuroergonomia, sendo este termo de origem recente com sua primeira menção em 2003 na edição especial da revista "Theoretical Issues in Ergonomics Science", para posteriormente consolidar-se com o lançamento do livro Neuroergonomics: The Brain at Work (PARASURAMAN; RIZZO, 2007).

Esta ergonomia preocupada com o bem estar do indivíduo, invocada ao buscar-se adequação no desenvolvimento do trabalho, atenta aos aspectos físicos, organizacionais e cognitivos envolvidos no labor do ser humano, espraia seu raio de ação e encontra os estudos do ambiente construído e habitado, lugar onde 
em última análise, todas as tarefas e atividades acontecem. Surge a ergonomia do ambiente construído (EAC), ou, a ergonomia aplicada aos ambientes construídos, como aponta Mont'Alvão (2011).

Integrando a ideia do ambiente arquitetônico com o ambiente do desenvolvimento das tarefas, de acordo com as capacidades, habilidades e limitações humanas o que inclui características como percepção, compreensão e interação com o espaço - parece clara a necessidade dos conhecimentos da Ergonomia nos projetos de Design e a Arquitetura que comtemplam o ambiente construído (MONT'ALVÃO, 2011, p.14).

Sob tais premissas e considerando os relevantes avanços e estudos da neuroergonomia, seria natural trazer seus conceitos e ferramentas para os domínios da ergonomia do ambiente construído e todas as variáveis neles envolvidos.

O cérebro humano comanda as atividades e comportamentos das pessoas, que dependendo do ambiente pode ocorrer de maneira mais ou menos prazerosa, mais ou menos produtiva, ou causando mais ou menos bemestar (NASAR, 2008). Nesse contexto, Zeisel (2006) alerta para a importância dos conceitos da Neurociência como elemento de suporte na concepção de espaços com execução de direcionamentos, informações e estímulos adequados visando a promoção da segurança e bem-estar de seus usuários.

Karakas e Yildiz (2020) apresentam uma importante compilação das publicações, obtida por meio de revisão sistemática, sobre a abordagem neurocientífica adotada nos estudos de ambientes construídos na experiência humana. Representa seguramente uma grande contribuição à linha de trabalho que vem sendo seguida pelo grupo de pesquisa em Ergonomia Aplicada ao Ambiente Construído.

Ponderando que a "experiência humana em arquitetura e o ambiente construído tem sido estudado intensamente desde o 1960, mas o papel desempenhado pelo cérebro humano neste experiência foi recentemente introduzida no campo em início dos anos 2000", Karakas e Yildiz (2020) apoiam-se em Eberhard (2009) quando afirmam que a ideia de trazer o cérebro humano e suas sensações em relação ao ambiente construído foi introduzido em abordagens teóricas e metodológicas criando uma mudança paradigmática.

A revisão realizada pelas autoras aponta que a maioria dos conceitos foram desenvolvidos em termos teóricos, mas estudos experimentais ainda não conseguiram validar parte significativa dessas teorias. Mesmo sendo os trabalhos experimentais crescentes, o cenário mostra que a grande variedade de conceitos requer mais pesquisa, com um enorme potencial e fortes desafios. O relacionamento entre a experiência humana e o ambiente construído enfocado pelas abordagens da neurociência irá influenciar fortemente os estudos futuros, apresentando-se como uma área em plena ascensão.

Nesse panorama a cautela é fundamental a fim de evitar que a empolgação excessiva das novidades e as boas perspectivas das descobertas embacem conceitos primordiais. As ponderações de De Paiva (2018) devem ser observadas quando alerta que os espaços não afetarão, necessariamente, a todos da mesma forma, sendo imprescindível considerar o público alvo ao projetar um edifício. Não pode ser considerado que arquitetos adeptos da neuroarquitetura serão capazes de criar ambientes perfeitos, onde os cérebros funcionarão da melhor forma, porque mesmo que o cérebro possa ser programado para apresentar alguns comportamentos, ele é moldado pela cultura e experiências que os indivíduos têm durante suas vidas.

Nesse ponto ressalta-se a categorização de Arbib (2013) quanto à relação entre neurociência e arquitetura, importante para que seja não considerado apenas os conceitos derivados do exame dos cérebros dos indivíduos em termos de como eles respondem ao ambiente: (1) há a neurociência do processo de design, que examina cérebros de arquitetos; (2) a arquitetura neuromórfica, que examina o cérebro de edifícios; e (3) a neurociência da experiência arquitetônica, que examina os cérebros de indivíduos experienciando um ambiente construído. 
É nesse contexto que devem ser consideradas as salutares interseções entre a neurociência aplicada à arquitetura, a psicologia ambiental, a arquitetura comportamental, os princípios de biofilia e todos os demais ramos do conhecimento que se preocupam em melhorar a relação entre o humano e seus ambientes. Nesta direção, reproduz-se a conclusão de Karakas e Yildiz (2020) após a revisão sistemática qualitativa realizada.

A interseção da neurociência e a arquitetura provavelmente será benéfica para (1) avaliar o desempenho de um ambiente construído existente, (2) fornecer decisões de design baseadas em evidências e (3) melhorar a qualidade de vida do ser humano e da sociedade. $\mathrm{O}$ conhecimento neurocientífico pode fornecer dados baseados em evidências e dados objetivos cuja ausência até o momento tem sido um dos as maiores deficiências das teorias atuais em suas tentativas para examinar a experiência humana no ambiente construído. (KARAKAS e YILDIZ, 2020, p. 245)

Estas breves explanações acerca de tão vasto e complexo tema concorda com a afirmação de De Paiva (2018), quando coloca que a aplicação de neuroarquitetura segue caminho além de compreender o cérebro para criar mais espaços eficientes. É fundamental para os arquitetos possam entender os usuários do edifício, bem como a finalidade de tal edifício e cada espaço dentro dele. Ao considerar esses três fatores associados conhecimento do cérebro, propósito de construção e usuário, os arquitetos terão subsídios mais eficientes para projetar edifícios melhores e mais adequados.

\section{Desenho das Pesquisas}

As pesquisas aqui apresentadas são de fato partes de projetos mais amplos que aplicam técnicas e conceitos da neurociência aos estudos de ambientes edificados e urbanos, incluindo as questões de acessibilidade. São pesquisas exploratórias, de natureza aplicada, abordando os problemas de forma qualitativa, configuradas em estudos de casos.

Na definição das técnicas e instrumentos utilizados encontra concordância no texto de Vasquez et al. (2016) quando compilam os trabalhos de Tomsak (2005), Mehta \& Parasuraman (2013) e Correa (2008) para elencar como técnicas utilizadas na neuroergonomia, o EEG (eletroencefalograma) provedor de informações sobre a atividade cerebral em resposta aos estímulos cognitivos, a técnica de EPRs (EventRelated Potentials) configurada como uma medida objetiva para o seguimento de progressão ou respostas a terapias e a Realidade Virtual (RV), que consiste em gerar diferentes cenários virtuais com múltiplas aplicações científicas.

Karakas e Yildiz (2020) apresentam as técnicas e métodos de pesquisa relacionados ao ambiente construído e estudos da neurociência agrupados em três grandes blocos: 1 . ambiente e técnicas de pesquisa comportamentais; 2. técnicas de pesquisas em neurociências; 3 . ferramentas digitais. No primeiro bloco estão as medidas observacionais, medições de autorrelato, dados de arquivo e técnicas de mapeamento (mapa mental, mapa comportamental, mapa cognitivo, bio mapeamentos e mapeamentos com biossensores. Encontram-se no segundo bloco as medidas psicofisiológicas tais como as técnicas de neuroimagem onde se destacam o EEG, ERP, MEG, os sensores de pele para medição temperatura e condutância, as aferições de pressão e volume sanguíneos, frequência cardíaca, movimentos e piscar de olhos. Finalmente o terceiro bloco inclui os dispositivos de GPS, Eye tracking, Realidade Virtual, Realidade Aumentada, câmeras e microfones.

Abrangendo o intervalo temporal iniciado em 2015 e permanecendo em atividade até o presente momento, as pesquisas expostas neste artigo adotam técnicas citadas na literatura referenciada e tem seus percursos metodológicos e ferramentas utilizadas descritas nos próximos tópicos. 
Cabe esclarecer que as duas pesquisas aqui relatadas contaram com profissionais neurocientistas e da psicologia em suas equipes de execução, sem os quais não seria possível a aplicação dos equipamentos de EEG, análise e interpretação dos dados coletados.

\subsection{Estudo de ambientes residenciais de idosos}

A Realidade Virtual (RV) consiste na interação do usuário com um ambiente criado de modo digital, podendo ter respostas controladas, monitoradas e avaliadas (ARIAS et al., 2012). Portanto, como ferramenta tecnológica a RV é considerada recurso de impacto para compreensão científica de pesquisas nas mais diversas áreas de conhecimento científico que envolvem situações consideradas como condições perigosas cirurgia, setor aeroespacial, treinamento militar, entre outras (PARASURAMAN; RIZZO, 2007).

Essa técnica possibilita ao pesquisador a observação comportamental e neurofisiológica da mente e do cérebro em situações inapropriadas ou que possam vir a pôr em risco o usuário. Assim, relativamente ao ambiente construído, sobretudo aqueles destinados ao indivíduo idoso, a RV pode vir a contribuir como elemento preditor de inadequações espaciais, bem como auxiliar em correções de situações existentes.

Paralelamente a Neurociência aliada à Ergonomia tem se tornado uma ferramenta potencial para o conhecimento dos processos cognitivos e aprimoramento dos sistemas, onde o homem é o elemento central, conferindo o conforto, a segurança e a qualidade de vida no desempenho das atividades. E nessa direção, a exploração da capacidade da comunicação humana tem sido pesquisada nas mais diversas áreas, por meio de Eletroencefalografia (EEG), principalmente por ser considerada uma das medidas não invasivas. Exemplo desse campo de pesquisa são os estudos de Scherer et al. (2008) desenvolvidos para promover a interação do usuário com seu meio, através de navegação ou mesmo de execução de tarefas pré-definidas, onde a tomada de decisão voluntária é permitida.

Pfurtscheller (2010) aponta a Realidade Virtual como uma Interface-Humano-Computador poderosa devido à capacidade de oferecer campo de teste para procedimentos que simulem aspectos e situações reais. Nesse caminho, Evans e Blanke (2013) alertam para o potencial positivo da combinação de EEG com configurações de Realidade Virtual como elemento de estímulo visual, no qual o efeito de feedback da Interação Cérebro-Computador se apresenta de modo profícuo diante das várias possibilidades de aplicações (MUSSATTO, 2014).

Nesse cenário, auxiliada pela tríade da Realidade Virtual - imersão, interação e envolvimento - pela neurociência e, apoiada na Ergonomia do Ambiente Construído, foi investigada a percepção de usuários idosos sobre espaços de salas residenciais, entendendo sua interação simultânea e biunívoca com o ambiente.

Para tanto, a pesquisa aconteceu em duas etapas. A primeira tratou de compreender as preferências dos idosos quanto aos ambientes e seus atributos positivos e negativos, enquanto que a segunda se apropriou dos resultados da primeira etapa para simular ambientes e averiguar por meio da eletroencefalografia as emoções sobre esses espaços (Figura 1).

A pesquisa adotou como critérios de inclusão idosos com idade igual ou superior a 70 anos, no exercício de sua autonomia, não residente em ILPI, sem comprometimento cognitivo e com ausência de deficiência visual, devido ao fato de ser imperativa a visão binocular para a visualização das imagens em 3D. 


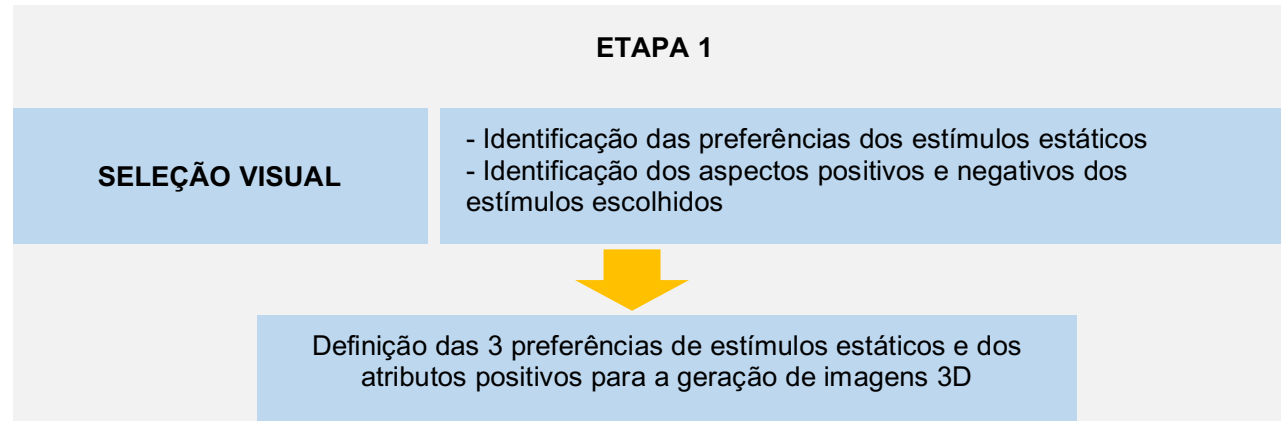

ETAPA 2

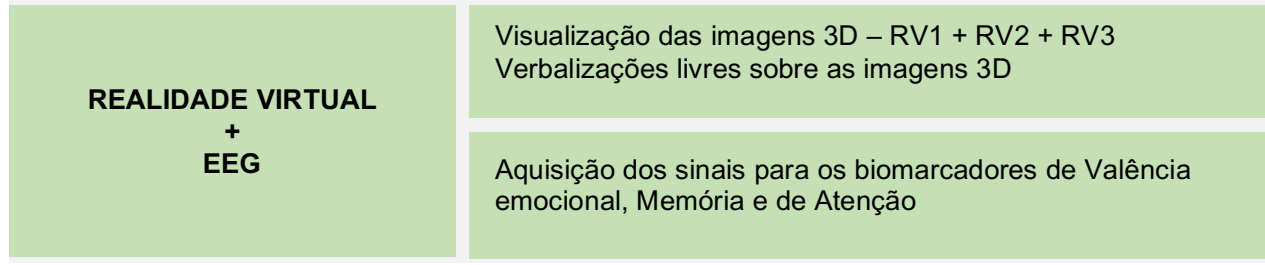

Figura 1 - Esquema metodológico para a pesquisa sobre percepção de idosos sobre espaços de salas residenciais. Fonte: arquivos da pesquisa

Assim, de modo aleatório e por indicação foram selecionadas 12 moradias de tipologias (casa e apartamento) e tamanhos diferentes para a capturas das imagens de salas. Da amostra total de usuários, cinco idosos foram excluídos do experimento - quatro deles manifestaram não desejar participar da pesquisa e um idoso era portador de visão monocular, condição não permitida para realização da etapa da investigação com uso da Realidade Virtual. Foram efetuados, portanto, levantamentos e registros fotográficos das doze moradias, entretanto só participaram da investigação na primeira etapa sete idosos com idades variando de 71 a 85 anos e integrantes de universos distintos quanto às classes sociais e nível cognitivo.

Após chancela de documento em cumprimento ao Comitê de Ética em Pesquisa envolvendo seres humanos da UFPE, foi efetuado o rastreamento cognitivo dos idosos participantes por meio do protocolo do Mini Exame do Estado Mental (MEEM), onde todos obtiveram escore válido para o nível de escolaridade adquirida de cada um dos entrevistados. Para a averiguação da capacidade funcional foram aplicados os protocolos de Katz e a escala de Lawton-Brody, que atestaram máxima independência para a realização das Atividades de Vida Diária (AVD) e para as Atividades Instrumentais de Vida Diária (AIVD). Tais resultados consideraram os sete idosos voluntários aptos para o estudo.

Para a segunda etapa do experimento que contemplou a visualização das imagens em RV associada ao EEG, dos sete idosos participantes iniciais, apenas cinco deles se disponibilizaram para a etapa de avaliação da percepção dos ambientes simulados. Desse modo, para essa fase a amostra foi constituída por idosos com idade variando entre 75 e 81 anos, com níveis de escolaridade e de sexos distintos. Apesar de principiantes no uso de óculos de RV, os idosos se mostraram receptivos e tranquilos, não externando constrangimentos ou desconforto algum na utilização do equipamento.

As aquisições dos sinais elétricos cerebrais foram realizadas por meio do equipamento de eletroencefalografia neuroBOX (neuroUP® - Brasil), com comunicação wireless para o computador é em combinação com o neuroCAP (neuroUP ${ }^{\circledR}$ - Brasil) - touca elástica com oito eletrodos de Ouro $(\mathrm{Au})$ distribuídos ao longo do encéfalo, com referência em processo mastoide esquerdo, com ground na posição em Fz. 


\subsection{Estudo de mobilidade urbana com pessoas cegas}

A pesquisa visa entender e avaliar as reações de pessoas cegas congênitas em deslocamento por percursos urbanos, estando em desenvolvimento na cidade de Fortaleza. No seu percurso metodológico adota conceitos, técnicas, tecnologias e procedimentos da neuroergonomia e do neurodesign, em um modelo que adota estes conhecimentos em processos avaliativos, notadamente onde o Design Universal e as rotas acessíveis são contemplados, objetivando trazer a percepção do usuário para dentro do projeto, traduzidos em atributos desejados e passíveis de serem entendidos com a mediação da neurociência na busca do entendimento dos movimentos e posturas das pessoas com deficiência nos seus deslocamentos diários.

É um estudo de casos múltiplos com dez pessoas cegas, selecionadas por facilidade de acesso, atendendo aos critérios de inclusão de ser cego congênito, estar apto a realizar caminhadas orientado por bengala e saber ler o braille.

Partindo do princípio de que a captação e análise das ativações de áreas cerebrais, por meio da utilização da eletroencefalografia (EEG), permite entender sensações de pessoas com cegueira ao enfrentar o desafio de caminhar em espaços urbanos, a pesquisa realiza o monitoramento do cérebro de uma pequena amostra de indivíduos que recebem a tarefa de percorrer caminhos pré-definidos.

A coleta de dados foi iniciada após a aprovação do projeto de pesquisa pelo Comitê de Ética em Pesquisa Envolvendo Seres Humanos, da Universidade Federal do Ceará.

Os passos metodológicos para a coleta de dados com os usuários estão ilustrados no esquema da Figura 2.

\section{Primeira etapa da coleta}

Chegada ao ponto inicial realiza teste de stress de LippGrava EEG de linha de base Escuta do primeiro trecho do percurso com touca e gravação
Realização do percurso com monitoramento de frequência cardíaca - gravação de voz filmagens e fotos. A equipe de pesquisa acompanha.
Chegada ao local definido realiza novo EEG para registro das ativações cerebrais após o percurso que foi memorizado para realização.

\section{Segunda etapa da coleta}

Neste local e ainda com a touca recebe mapa tátil onde vai definir o segundo trecho do percurso. A equipe não opina na escolha do caminho.
Realização do percurso com monitoramento de frequência cardíaca - gravação de voz filmagens e fotos. A equipe de pesquisa acompanha.
Chegada ponto final - realiza novo EEG - identificação de ativações e sensações após percurso definido por ele mesmo no mapa tátil.

Figura 2 - Esquema metodológico para pesquisa de campo com voluntários cegos Fonte: arquivos da pesquisa

Para realização do EEG utiliza-se touca em Neoprene com cabeamento em Prata de lei 925 e 950, proteções com tubulações termo retráteis, serial de 25 pinos, malha náutica, capas de eletrodos em impressão $3 \mathrm{D}$ em material Tritan ht, equipamento para registro Icelera com 52 canais, sendo 20ch para EEG com mapeamento cerebral e vídeo-EEG, softwares que acompanham o equipamento para leitura, gravação com taxa de amostragem 512 . 
Os resultados das análises dos EEGs permitirão identificar quais são as áreas ativadas nos encéfalos dos voluntários da pesquisa, ao receberem instruções verbalizadas que devem ser memorizadas, a fim de realizar um percurso e alcançar um destino, bem como ao utilizar um mapa tátil para definir e memorizar sua rota para um deslocamento solicitado.

\section{Tecnologias Emergentes e Ambientes de Idosos}

Este trabalho é parte de uma pesquisa mais ampla, desenvolvida como tese de doutorado no Programa de Pós Graduação em Design da UFPE e que teve por objetivo utilizar técnicas da neurociência para entendimento das reações de pessoas idosas frente a ambientes residenciais. Integra um conjunto de trabalhos que avalia os resultados que se pode obter quando da inserção dessas ferramentas nos estudos de ambientes.

O crescente aumento do número de pessoas idosas é um fato inexorável. De acordo com o relatório Perspectivas da População Mundial: Revisão de 2017 (UN-ESA, 2017), a população mundial está envelhecendo a passos largos, devido ao aumento da longevidade e à baixa taxa de natalidade registrada. Nesse cenário, a população brasileira acompanha as métricas mundiais onde, segundo a Pesquisa Nacional por Amostra de Domicílios, o número de idosos já representa 12\% da população total (IBGE, 2017). Tal índice sinaliza um rápido envelhecimento do país associado à uma maior longevidade, ocasionando uma convivência intergeracional nunca antes registrada.

Diante das mais variadas temáticas envolvendo os interesses dos idosos, a preocupação com a moradia se destaca, devido ao seu viés qualitativo, na medida em que se constitui mediadora do bem-estar e da segurança, com repercussões para a qualidade de vida, não só para os idosos atuais, mas para aqueles hoje jovens e adultos que enfrentarão a velhice futura.

O envelhecimento é caracterizado como processo biológico e individual, no qual ocorrem alterações anatômicas e funcionais, não decorrentes de doenças, (FECHINE; TROMPIERI, 2012), e que compreende a velhice, fase em que ocorre o declínio físico. Contudo, a velhice não se limita exclusivamente ao modelo de envelhecimento biológico; as pessoas envelhecem de modos diferentes com experiências psicossociais, culturais e de saúde distintas - determinantes para suas idades fisiológicas - mesmo apesar de apresentarem idades cronológicas semelhantes.

Para Fernández-Portero et al. (2017), a adaptação física e do contexto de espaços residenciais influencia diretamente a percepção da satisfação de pessoas idosas e a sua qualidade de vida nos espaços habitacionais. Segundo Vaughn (2015) os efeitos de um ambiente esteticamente agradável são determinantes na condição de bem-estar psicológico das pessoas e na promoção de espaços confortáveis de vivência prazerosa. Johnson (2009) afirma que a arquitetura representa, mesmo que de modo inconsciente, uma forma de linguagem em diálogo constante e interativo entre as pessoas e o ambiente (DE PAIVA, 2018), seja por funcionalidade, valores estéticos, ou culturais.

Assim, entende-se que os espaços físicos são determinantes para as pessoas, no tocante à realização de atividades, bem como aos sentimentos provocados por esses espaços nos usuários. Por outro lado, aos ambientes físicos de moradia é remetido o conceito de identidade do lugar com a criação de vínculos emocionais e afetivos, além de representações concretas e simbólicas, impondo ao espaço o sentido de lugar, a partir das experiências e vivências de seus usuários (TUAN, 2013).

E nessa dimensão há que se considerar as alterações naturais no processo do envelhecer, uma vez que o usuário assume relação de influência mútua com os ambientes, conservando aspectos que concorrem para a qualidade do envelhecimento. 


\subsection{Seleção de estímulos visuais estáticos de ambientes residenciais de sala}

Dentre os ambientes que compõem a habitação, o espaço de sala foi selecionado para a análise desse estudo, entendendo ser um ambiente de permanência prolongada para os idosos, onde é possível agregar atividades de naturezas diversas, sem que tenha sua intimidade prejudicada. Boueri Filho (2008) ressalta que os ambientes residenciais de sala apresentam a função de "estar e lazer", onde se desenvolvem atividades relacionadas ao estar passivo, a receber visitas, à diversão, ao lazer em família, a eventos sociais, e outras.

A reação humana aos estímulos visuais presentes no ambiente é decorrência das informações obtidas nesse ambiente segundo dois níveis de interpretação. Segundo Kaplan (1988) as pessoas reagem tanto ao padrão bidimensional (fotografia) quanto ao padrão tridimensional dos espaços que envolvem essas pessoas Assim, a complexidade (BERLYNE, 1972) ou diversidade, é o elemento de envolvimento para a análise ao nível de interpretação bidimensional, enquanto que a coerência é o componente do "fazer sentido", e que tem no contraste a dimensão de identificação dos elementos em cena.

Entretanto, os aspectos fiscos-formais, como conforto ambiental, funcionalidade e uso dos espaços físicos, exercem influência sobre o comportamento de seus usuários. Essa característica assume significativa importância quando o usuário é o indivíduo idoso, uma vez que sua percepção sobre o ambiente vivenciado nem sempre espelha a realidade, devido ao déficit cognitivo característico da idade. Também a expressão de seus sentimentos sobre esses ambientes nem sempre se faz corresponder com a realidade sentida, por não querer desagradar. Muitas vezes são externadas opiniões com o objetivo de satisfazer quem as solicitou do que de fato o que se tem em mente.

Dessa forma, foram adotadas fotografias impressas em cores e no tamanho $10 \times 15 \mathrm{~cm}$ como estímulo visual estático para identificar as preferências visuais de idosos em ambientes residenciais. Devido à incerteza de que os espaços fossem de fato vivenciados por pessoas com sessenta anos ou mais, foram registradas imagens de ambientes de sala de moradias habitadas pelo indivíduo idoso - todos funcionalmente independentes - sendo descartadas, portanto, imagens selecionadas por meio eletrônico (internet) ou mesmo impresso sem qualquer referência à natureza etária do morador investigado (pessoa idosa).

Do total de registros fotográficos efetuados nas moradias analisadas foi executada uma triagem considerando ângulo mais significativo para a caracterização do ambiente real para visualização dos elementos e nível de iluminação mais adequado. As imagens foram separadas por tipologia (casa e apartamento) e foi analisado o número de elementos presentes na composição dos ambientes e estabelecido o grau de complexidade - alto; médio e baixo - para cada uma das fotografias selecionadas como parte integrante do corpo amostral de 24 (vinte e quatro) estímulos visuais estáticos. Para Ham et al. (2004), a complexidade é um elemento na produção de ambientes ricos em informações e que convida ao envolvimento do usuário com o espaço, na perspectiva de que esse envolvimento é essencial para a descoberta de informações e manutenção da atenção.

A partir de Sanoff (1991) foi solicitado aos idosos participantes da primeira etapa da pesquisa escolher e classificar em ordem decrescente de preferência, e segundo critérios por eles estabelecidos, cinco estímulos visuais estáticos (ambientes de sala residencial) do universo amostral - numerados de um a 24 em seu verso para identificação das imagens selecionadas. As escolhas dos entrevistados foram dispostas em tabela para identificar os três ambientes de sala de maior preferência dos idosos, assim como também os aspectos positivos e negativos mais recorrentes em citação por eles.

E na busca de resultados assertivos sobre a correspondência do sentir (emoções sobre os ambientes) e expressar (verbalizações sobre esses ambientes) se fez uso da Realidade Virtual associada ao EEG com imagens 3D que expressaram as preferências de idosos quanto a ambientes de salas residenciais. 


\subsection{Simulação dos ambientes e visualização $3 D$ associada ao EEG}

A Realidade Virtual é uma técnica avançada que se utiliza dos canais multissensoriais humanos, e com maior frequência do canal visual auxiliado por dispositivos como, por exemplo, os óculos de Realidade Virtual (KIMER, C; KIMER, T., 2011). O uso dessa tecnologia proporciona ao usuário a vivência de ambientes tridimensionais imaginários, e ainda permite que objetos desse ambiente sejam manipulados virtualmente, a partir de geração de imagem por computador.

Como tema correlato à Realidade Virtual situa-se a neurociência com a utilização da eletroencefalografia para entendimento de tarefas onde há solicitação da cognição espacial durante movimentos. As imagens tridimensionais devem ser interpretadas pelo cérebro humano como um objeto 3D. Esse comando de transformação mental exige uma cognição nem sempre presente em usuários para a criação de representações a partir de planos bidimensionais.

Nesse cenário, o processo de elaboração da visualização das imagens em 3D nessa investigação envolveu duas etapas físicas - seleção de estímulos estáticos e aplicação da Seleção Visual (SANOFF, 1991) - e uma analítica, compreendendo a definição dos elementos de composição e o processo de modelagem e renderização de cada uma das imagens.

Os estímulos visuais estáticos obtidos como os de maior preferência pelos idosos foram alterados em suas composições originais com os atributos desejáveis e não desejáveis apontados, modelados através do programa gráfico SketchUp. Após a renderização 3D as imagens foram visualizadas pelos idosos voluntários (Figura 3) por meio de Realidade Virtual imersiva, com a utilização dos óculos Gear VR, marca Samsung, em uso simultâneo de equipamento de eletroencefalografia wireless.
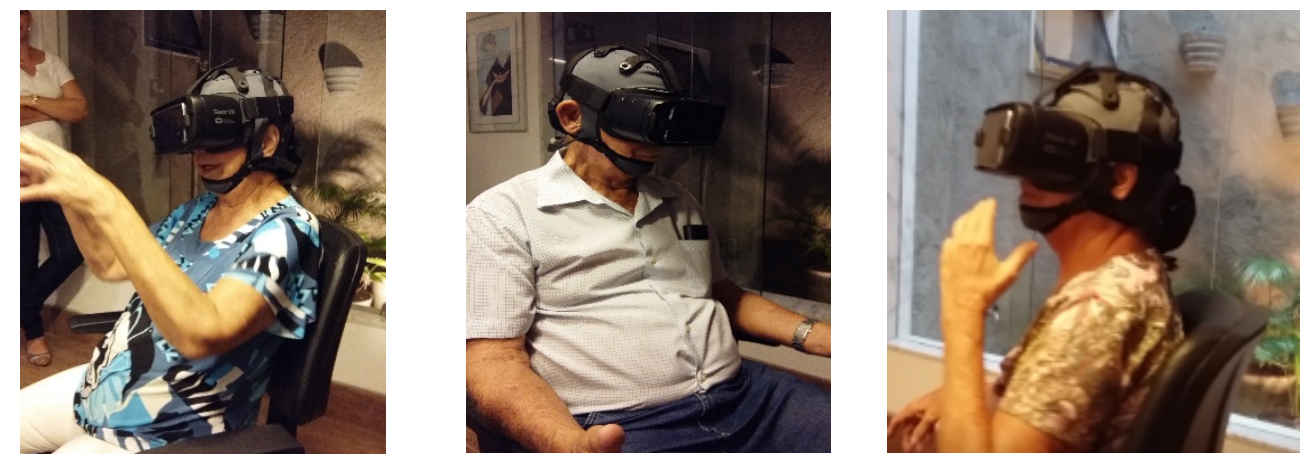

Figura 3 - Idosos voluntários com óculos RV e com a touca de EEG.

Fonte: arquivos da pesquisa

Contudo, as modificações das características dos espaços residenciais reais de sala com os atributos apontados como positivos e negativos na etapa inicial da Seleção Visual acarretaram em alteração do nível de complexidade dos ambientes originais. A moradia M-1 (casa) que foi classificada inicialmente como de baixa complexidade, após manipulação dos elementos compositivos do espaço passou a ser reconhecida por $\mathrm{RV} \mathrm{n}{ }^{\circ} 1$ e classificada como de alta complexidade. A moradia $\mathrm{M}-2\left(\mathrm{RV} \mathrm{n}^{\circ} 2\right)$ categorizada como de média complexidade passou a ser de baixa, enquanto que a moradia $\mathrm{M}-3$ ( $\left.\mathrm{RV} \mathrm{n}^{\circ} 3\right)$ identificada como de alta complexidade foi manipulada para complexidade intermediária.

Com o equipamento de EEG acondicionado corretamente e executada a estabilização dos sinais cerebrais, as imagens 3D foram visualizadas por dois minutos, em silêncio, para a captação dos impulsos elétricos e comparação do envolvimento de cada idoso com cada uma das imagens tridimensionais, assim como entre os idosos por cada imagem. Após esse tempo, se iniciaram as verbalizações livres com relação às impressões sobre o estímulo visual dinâmico, sendo todo o processo de aquisição e manifestações verbais gravados e 
filmados para posterior transcrição e análise dos dados. Para cada idoso pesquisado foram efetuadas três aquisições, totalizando 15 eventos.

Entre as três imagens de Realidade Virtual, a RV n ${ }^{\circ} 1$ - classificada como de baixa complexidade - foi a que apresentou menor tempo de visualização para os cinco idosos pesquisados, enquanto que a RV n 3 (classificada como de alta complexidade) foi a imagem 3D que em maior espaço de tempo foi visualizada por todos os idosos pesquisados. A RV n 2 (classificada como de complexidade intermediária) foi a imagem 3D escolhida como ideal por três dos cinco idosos pesquisados. Tal fato pode ser observado de acordo com o comentário do idoso I-1: "[...] tá tudo muito lindo. O ambiente é bem arrumado. Ambiente bom para a gente permanecer nele. O ambiente é claro, do jeito que eu gosto. Se você chegar nesse ambiente com algum problema, o problema passa, porque é um ambiente gostoso!", ou até mesmo na fala do I-4: "Eu gostei mais desse ambiente. Na minha visão eu estou vendo um espaço com dois ambientes, com d poltronas. Está mais alegre, mais ornamentado, de mais bom gosto".

Os sinais cerebrais obtidos durante as visualizações das imagens 3D foram decompostos em ritmos Alfa, Beta, Theta, Gama e Delta usando a análise de tempo-frequência para os biomarcadores de Valência Emocional, índice de Memória e índice de Atenção. Assim, para uma melhor compreensão estão representados nos gráficos que se seguem os estímulos visuais dinâmicos (imagens 3D), na cor azul para a $\mathrm{RV} \mathrm{n}^{\circ} 1$ (baixa complexidade), na cor verde para a $\mathrm{RV} \mathrm{n}^{\circ} 2$ (média complexidade) e na cor roxa para a $\mathrm{RV} \mathrm{n}^{\circ} 3$ (alta complexidade).

O centro do pensamento e das emoções localiza-se no córtex frontal e tem como objetivo mensurar a assimetria do córtex frontal. Assim, para biomarcador de Valência Emocional os dados coletados evidenciaram que o ambiente de baixa complexidade ( $\left.R V n^{\circ} 1\right)$ evocou emoções positivas, e os ambientes de média $\left(\mathrm{RV} \mathrm{n}^{\circ} 2\right)$ e de alta $\left(\mathrm{RV} \mathrm{n}^{\circ} 3\right)$ complexidade evocaram emoções negativas, progressivamente, conforme se observa no Gráfico 1.

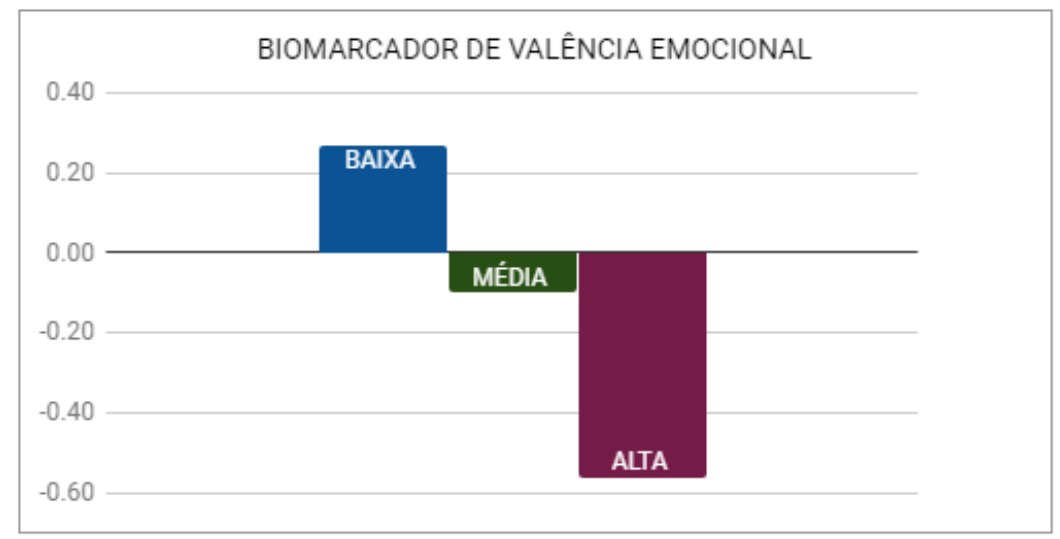

Gráfico 1: Aquisições de sinais elétricos cerebrais para o biomarcador de Valência Emocional. Fonte: arquivos da pesquisa

Observa-se que os valores registrados menores do que zero representam emoções negativas, significando evitamento (withdraw). Para os valores representativos maiores do que zero são atribuídas emoções positivas, expressando aproximação (approach). Assim, a imagem em Realidade Virtual referente ao ambiente de sala com alta complexidade ( $\mathrm{RV} \mathrm{n}^{\circ} 3$ ) foi a imagem que registrou o maior valor negativo, portanto, não provocou emoção positiva nos idosos investigados. Entretanto, a RV de baixa complexidade $\left(\mathrm{RV} \mathrm{n}^{\circ} 1\right)$ foi aquela que mais positivamente evocou emoção nos idosos.

Corroborando as métricas do EEG identifica-se o discurso do idoso I-7 para a $\mathrm{RV} \mathrm{n} \mathrm{n}^{\mathrm{0}} 1$ "Está bonito! $O$ ambiente é simples e gostoso" e do idoso I-6 "A sala é interessante, não faz mal a ninguém. O ambiente é pequenininho, mas arrumadinho". Para a RV n'2 o idoso I-7 manifestou: "Está mais alegre, mais 
ornamentado, de mais bom gosto. Está mais espaçoso que o outro. Serve para você sentar e jantar e do outro lado para conversar, tomar um vinhozinho... (sorrisos)". Já para a imagem de alta complexidade (RV $\mathrm{n}^{\circ} 3$ ) o idoso I-4 afirmou: "Acho esse ambiente pequeno. É muito acanhado; muito pequeno. A decoração é até agradável. Cheio de quadro. Tem muita porta".

Para o biomarcador de Memória a aquisição dos impulsos elétricos nos idosos investigados foi selecionado o eletrodo T3, localizado no hipocampo esquerdo, na área do lobo Temporal. A análise dos resultados dos EEG demonstra que a ativação da memória aumentou progressivamente com o aumento da complexidade dos ambientes. A imagem $3 \mathrm{D}$ de alta complexidade ( $\left.\mathrm{RV} \mathrm{n}{ }^{\circ} 3\right)$ foi a que mais provocou a ativação de memórias anteriores para o reconhecimento das informações apresentadas na Realidade Virtual imersiva (Gráfico 2).

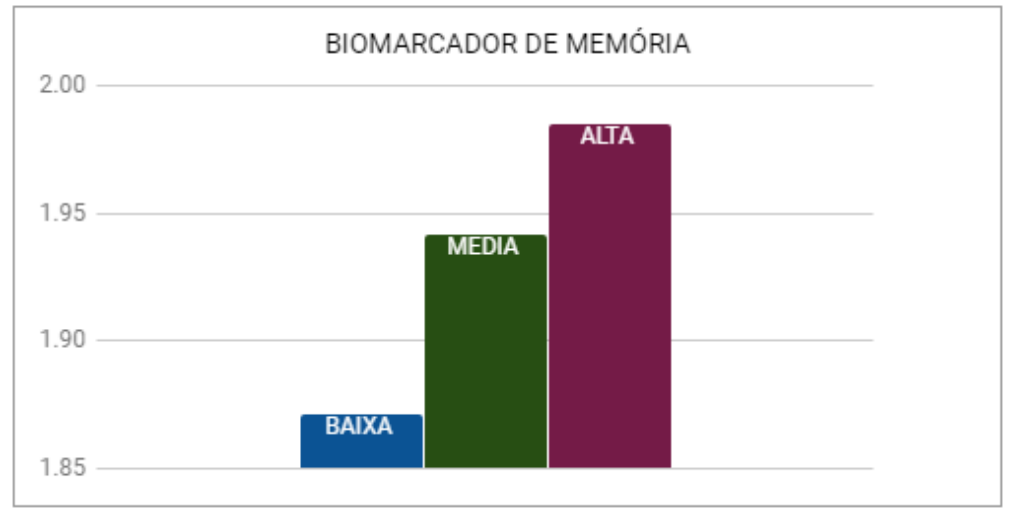

Gráfico 2: Aquisições de sinais elétricos cerebrais para o biomarcador de Memória.

Fonte: arquivos da pesquisa

Essa afirmação encontra eco na insatisfação clara presente na verbalização do idoso I-2 para a RV no 3 (Alta complexidade): "[...] é mais descontraído, apesar de estar tudo entulhado. É muito enfeitado demais! $O$ ambiente escurece por conta do teto ... não gosto do teto, não gosto das pinturas; aqui é tudo muito excitante".

Contudo, para a imagem 3D de baixa complexidade ( $\mathrm{RV} \mathrm{n}^{\circ}$ 1), o idoso I-6 se manifestou como satisfeito conforme relato:

\footnotetext{
"Está bonito! O ambiente é simples e gostoso. Mesa bem grande, larga. Planta deixa tudo mais relaxante; gostei. É uma sala gostosa; só essa janela aí bem iluminada e bem clara já dá boa impressão. Eu gosto muito de claridade! As almofadas listradas são bonitas; poltronas gostosas; eu vejo que é bem agradável."
}

Entretanto, a RV n ${ }^{\circ} 1$ (baixa complexidade) foi aquela que apresentou um menor índice de recrutamento da memória, provocando, assim, um menor resgate da atividade do reconhecimento de informações anteriores.

O biomarcador de Atenção tem relação direta com a ativação da via de atenção no córtex frontal. O ritmo Beta é gerado no córtex e é presente em situações de demanda de atenção, enquanto que o ritmo Theta é gerado em regiões profundas e tem ligação com a introspecção e redução de atenção ao ambiente. O índice é calculado através da razão Beta/Theta no eletrodo $\mathrm{Cz}$ e a interpretação é que este indicador é aumentado quando o participante intensifica a atenção ao ambiente externo.

O estado de alerta deflagra o processo de recepção dos estímulos resultantes dos canais sensoriais, variando, segundo Nahas (2001) para as formas de Atenção sustentada (estado de alerta por um período); Atenção dividida (desempenho simultâneo de tarefas) e Atenção seletiva (direcionamento voluntário para determinado interesse). 
Nessa direção, o Gráfico 3 evidencia o resultado das aquisições de impulsos neurais para o biomarcador de Atenção.

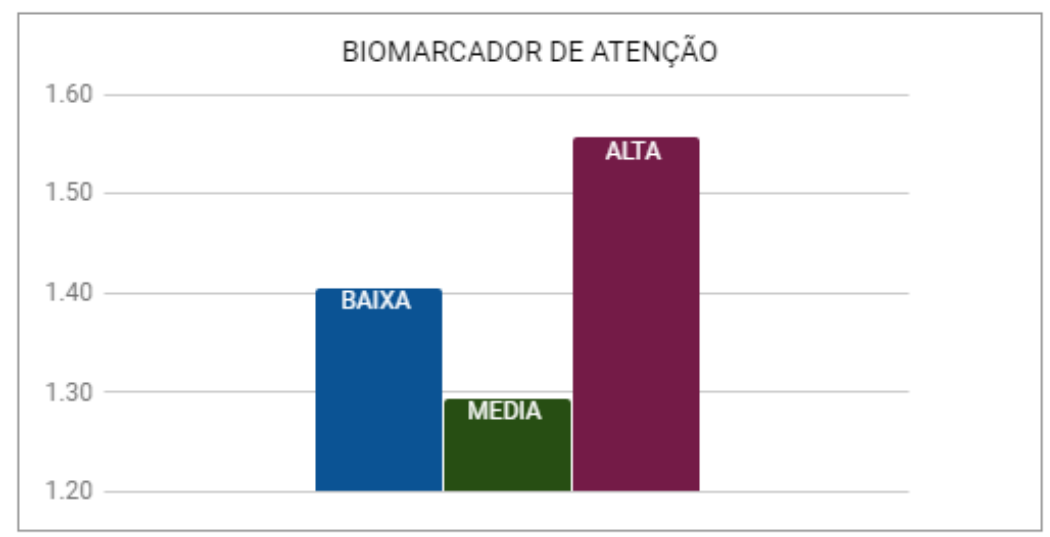

Gráfico 3: Aquisições de sinais elétricos cerebrais para o biomarcador de Atenção.

Fonte: arquivos da pesquisa

Observa-se no Gráfico 3 que entre as três imagens tridimensionais visualizadas pelos idosos pesquisados, a $\mathrm{RV}$ de ata complexidade $\left(\mathrm{RV} \mathrm{n}^{\circ} 3\right)$ apresentou o maior índice, e consequentemente foi aquela que mais chamou atenção. Contudo, isoladamente não se pode afirmar que o parâmetro do nível de atenção para a RV $\mathrm{n}^{0} 3$ tenha evocado mais sentimentos positivos.

Entretanto, analisando os indicadores de Atenção em conjunto com o biomarcador de Valência Emocional, os resultados sugerem que a imagem de alta complexidade ( $\left.\mathrm{RV} \mathrm{n}^{\circ} 3\right)$ foi aquela que mais chamou a atenção dos idosos, porém de modo negativo. Também o biomarcador de Memória identifica a imagem de alta complexidade ( $\mathrm{RV} \mathrm{n}^{0} 3$ ) como sendo aquela que mais suscitou o repertório de experiências anteriores.

Sobre o ambiente tridimensional de alta complexidade as verbalizações livres do idosos vêm ratificar os resultados das aquisições dos impulsos elétricos, de acordo com a afirmação do idoso I-7: "Totalmente diferente dos anteriores. Os quadros são pequenininhos. O tamanho da sala é meio acanhado. A sala é pequena, aí os quadros são tudo agarradinho; tinha que distribuir mais. Um quadro dá muita vida numa sala", assim como do idoso I-2 que falou: "O ambiente é muito apertado... É muito pequeno o ambiente. Aqui é uma sala. É mais descontraído, apesar de estar tudo entulhado. Aqui é tudo muito excitante. Pelo menos tem vida. Eu aqui não ia ficar calma não..."

A imagem 3D de média complexidade foi aquela que menos ativou o córtex frontal, indicando, assim, uma baixa ativação da atenção e, portanto, quando associada ao biomarcador de Valencia Emocional, constitui-se na imagem de maior preferência.

A experiência da Realidade Virtual imersiva para os ambientes residenciais de sala possibilitou uma apreensão espacial maior, fortalecendo a condição de interação do usuário com o objeto de estudo, e relacionando a emoção como fator humano presente nas expectativas dos idosos participantes relativas ao ambiente residencial de sala.

\section{Mobilidade Urbana de Pessoas Cegas Assistida por Neuro e Bio Marcadores}

Esta pesquisa está focada na efetividade de ferramentas de Tecnologia Assistiva (TA) auxiliares ao deslocamento e mobilidade de pessoas com cegueira em percursos urbanos. Está inserida nos domínios da neuroergonomia, neuroergonomia e neuroacessibilidade e investiga a utilização do EEG para mapear as sensações que indivíduos cegos experimentam ao enfrentar a aridez das vias urbanas de pedestres, deslocar- 
se a partir de informações verbalizadas vindas pessoas videntes, ou deparar-se com uma TA pouco utilizada nas cidades brasileiras e sobre as quais não tem domínio. O estudo está em curso sendo ainda preliminares os resultados, no entanto já se consegue vislumbrar comprovações da forte relação entre as reações cerebrais dos pesquisados e as estratégias utilizadas para informar os percursos a serem percorridos. A pesquisa foi apreciada e aprovada pelo Comitê de Ética em Pesquisa da Universidade Federal do Ceará.

Expõe-se aqui parte do trabalho realizado em um primeiro caso estudado. Os sinais cerebrais são captados em cinco momentos distintos a fim de comparar as os achados das coletas. No momento inicial, após a realização do Inventário de Sintomas de Stress para Adultos de Lipp (ISSL), a touca do EEG (Figura 4) é posicionada na cabeça do pesquisado para a captação denominada Linha de Base 01 (Figura 5), que sendo o momento que se inicia com o participante, pode registrar tranquilidade e pouca ativação dos lobos encefálicos. Nesta primeira etapa as informações e orientações sobre os procedimentos são declarados o que gera atenção e concentração no que está sendo transmitido.

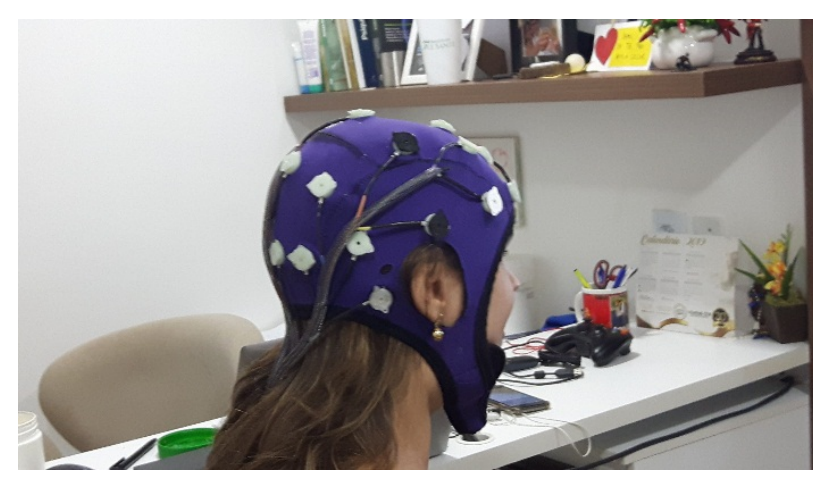

Figura 4 - Voluntária com a touca de EEG. Fonte: arquivos da pesquisa

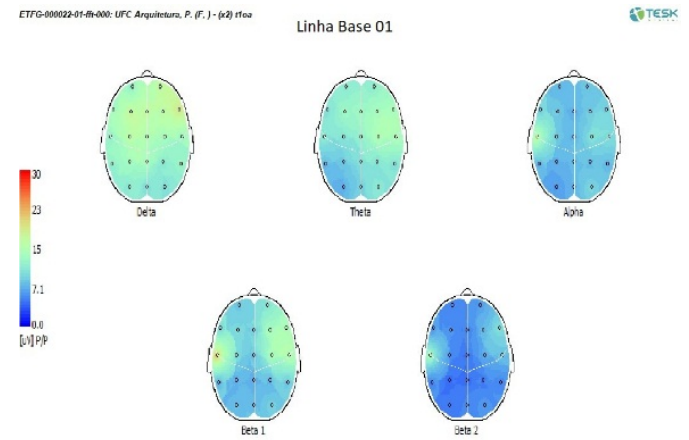

Figura 5 - EEG na Linha de Base 01. Fonte: arquivos da pesquisa

O cérebro trabalha com funções elétricas em frequencias definidas como Delta, Theta, Alfa, Beta e Gama, e nesta pesquisa as ondas mais importantes são Alfa e Beta. Villarouco et al. (2020) discorrem resumidamente sobre as características destas ondas esclarecendo que Alfa é considerada uma onda de frequência média e está relacionada a relaxamento ou uma atenção moderada, tranquila; Beta que é média-alta tem três subdivisões e varia de um estado cognitivo leve, passando por planejamentos e raciocínios, até a High Beta que está vinculada à ansiedade, medo, tensão e preocupação. As ondas Theta e Delta são leves e Gama são as mais altas com grande complexidade.

Para a interpretação das imagens mostradas na Figura 5, como também nas demais imagens que mostram as leituras encefálicas, cabe esclarecer que a cor azul forte representa ausência de ativação e que esta vai aumentando à medida que se aproxima do amarelo, alaranjado e vermelho como ativação máxima da região onde se apresenta.

Essas imagens são vistas de cima da cabeça, onde se pode identificar quais regiões cerebrais foram ativadas, quando abaixo de cada cabeça encontra-se identificada a qual tipo de onda corresponde. Nesta Figura 5 foi identificada uma ativação de ondas lentas e médias (Delta, Theta e Alfa), dentro do padrão da normalidade para a faixa etária em repouso ou pouca atenção. Já nas bandas de frequências Beta 1 e Beta 2 houve ativação mais significativa das áreas temporais. Com esses resultados verifica-se que nesta etapa do EEG a pessoa pesquisada apresenta processamento de função auditiva ou de imagética. De fato, ela estava ouvindo como aconteceria a coleta de dados e sua participação naquele momento da pesquisa.

Visando auxiliar no entendimento das áreas encefálicas referidas no texto, a Figura 6 apresenta esquematicamente as divisões do cérebro para efeitos de estudos. 


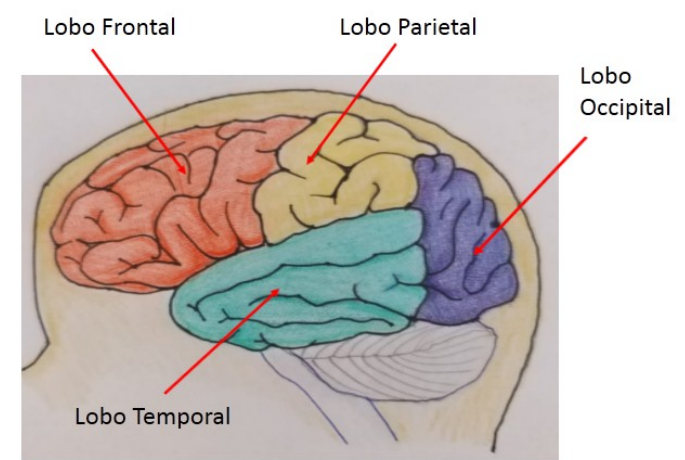

Figura 6 - Regiões dos Hemisférios Cerebrais (Ilustrativo). Fonte: elaborado pelos autores

Cada um dos lobos está relacionado a funções específicas, sendo basicamente o frontal relacionado à execução, raciocínio, trabalho; o parietal ao sensório motor, ligado à espacialidade, mobilidade e também ao sensitivo; occipital à visão e o temporal à audição. Diversas funções derivam destas que estão apresentadas com significativo nível de simplificação.

Na continuidade e, ainda com a gravação do EEG ativada, passa-se a explicar o caminho a ser percorrido até alcançar o primeiro ponto definido do percurso a ser realizado. O sujeito pesquisado é esclarecido que a equipe de pesquisa que estará acompanhando o percurso não vai interferir no seu trajeto, portanto, ele deve estar atento e memorizar os detalhes de travessias, viradas à direita ou esquerda e local de destino. $\mathrm{O}$ resumo do EEG nessa escuta está na Figura 7 onde se vê que baixam as ondas Alfa, baixam muito as ondas Beta 2, mostrando que não há ansiedade e também Beta 1 com muita redução, com um leve aumento apenas nas áreas temporais. Pode-se inferir que, quando a voluntária está escutando permanece muita tranquilidade, mais relaxamento. Apresenta bem menos Beta 1, Beta 2 e Alfa, que o visualizado na Figura 5.

De fato, a escuta é o processo mais usual para as pessoas cegas se deslocarem num determinado trajeto. Via de regra as pessoas videntes explicam o caminho, elas memorizam e seguem auxiliadas por suas bengalas que é a Tecnologia Assistiva (TA) mais usada para a caminhada. Isto pode explicar a tranquilidade registrada, sendo apenas solicitado que fosse repetida a instrução a fim de melhor fixar os detalhes.

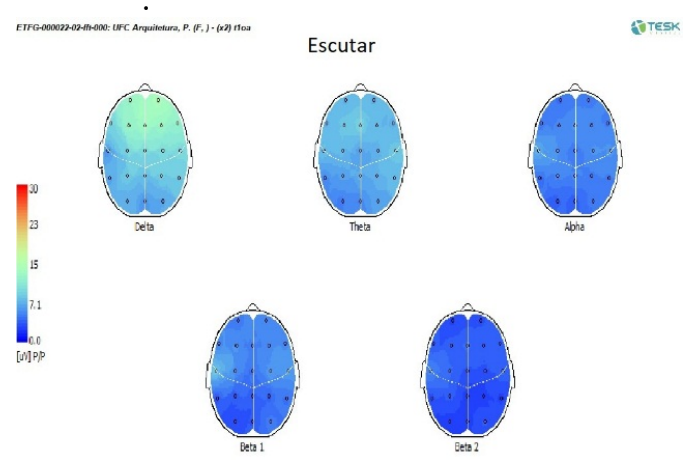

Figura 7 - EEG na Escuta.

Fonte: arquivos da pesquisa

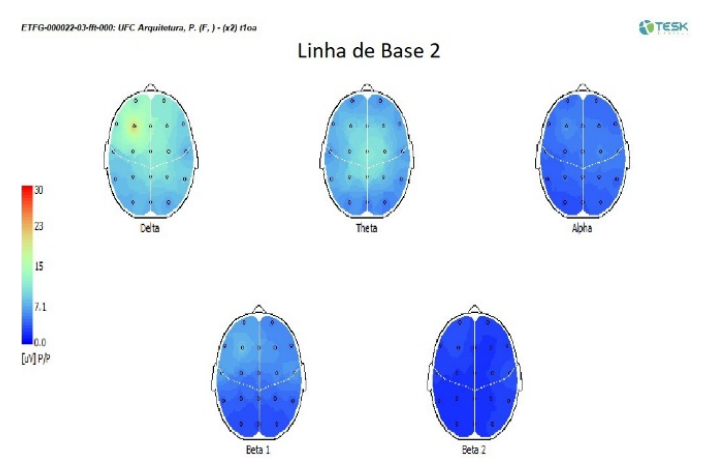

Figura 8 - EEG na Linha de Base 02

Fonte: arquivos da pesquisa

Vencida a primeira etapa do percurso, realiza-se nova gravação do EEG (Figura 8) ao chegar no ponto de destino. Verifica-se neste muita tranquilidade, ausência da ansiedade, com Beta 2 baixo, Alfa baixo, um pouco de Beta 1 registrado do lado esquerdo da cabeça, podendo indicar uma função mais positiva, por ser o hemisfério esquerdo muito positivo, identificando-se no geral pouquíssima alteração. O caminho foi percorrido sem dificuldades, estresses ou erros. 
Para continuidade do trajeto um mapa tátil é entregue ao pesquisado informando que o segundo trecho seria definido por ele a partir daquela TA que lhe estava sendo entregue. Nesta etapa apenas foi esclarecido que os pontos principais estavam identificados no mapa (local onde estava, ponto de destino e um ponto condicionante por onde teria de passar), e que ele deveria traçar sua rota, memorizá-la, para continuar em seguida. As imagens da gravação desta fase do EEG estão na Figura 9.

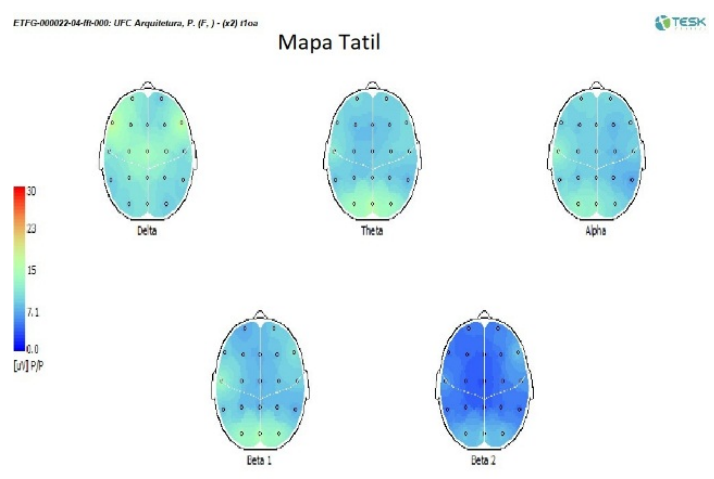

Figura 9 - EEG com o Mapa Tátil Fonte: arquivos da pesquisa

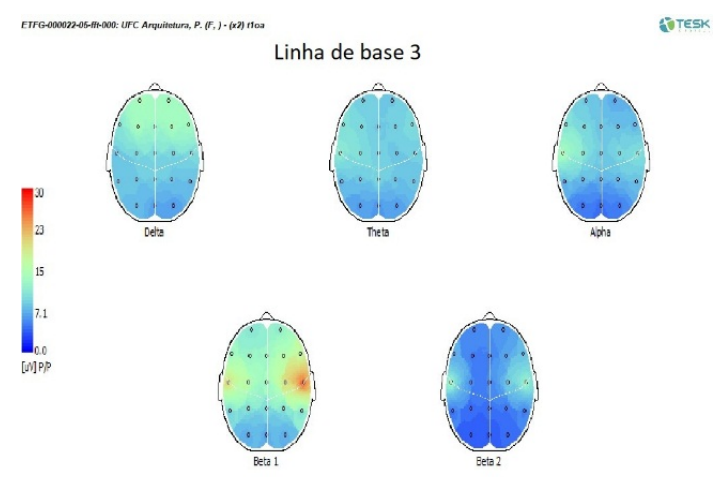

Figura 10 - EEG na Linha de Base 03 Fonte: arquivos da pesquisa

Ao passar a manusear o mapa tátil para entendimento e memorização da próxima etapa, o EEG (Figura 9) começa a apresentar alterações mais fortes, com ativação em Beta 1 que indica pensamento, raciocínio, cálculo, tanto nas regiões temporais e nas temporo-frontais, como toda a parte posterior que é a occipital; apresenta ansiedade em Beta 1 principalmente nas regiões temporais, deixando evidente que ela ficou mais ansiosa, com o cérebro trabalhando muito mais, gastando energia para perceber e aprender o caminho.

Mapas táteis não são comumente encontrados nas cidades brasileiras podendo ser esta umas das explicações para o registro da ansiedade. O receio de não ter sucesso na definição do percurso, de não conseguir sair-se bem no trajeto causa tensão na pesquisada (Figura 11), mesmo sabendo ser acompanhada pela equipe de pesquisa em todo o tempo (Figura 12).

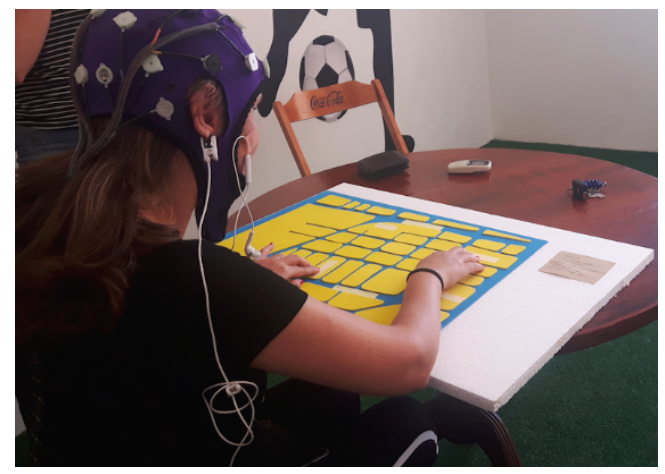

Figura 11 - Pesquisada com o Mapa Tátil. Fonte: arquivos da pesquisa

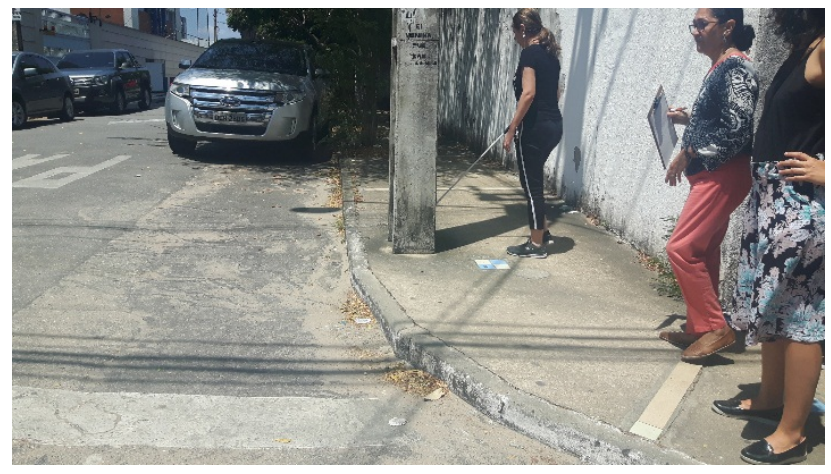

Figura 12 - Imagem do trajeto. Fonte: arquivos da pesquisa

Na Figura 10 onde se tem a gravação da linha de base da chegada ao ponto final, se percebe uma grande ativação em Beta 1 no cérebro inteiro, mais notadamente nas regiões temporais, inclusive com Beta 2 , indicando que foi mais complicado para ela cumprir a tarefa nesta função. Neste percurso, ela apresentou uma forte dúvida na penúltima rua a atravessar, pensando ser esta já a última rua onde deveria dobrar logo à esquerda, quando de fato ainda havia uma quadra a percorrer. Neste ponto, foi preciso a intervenção da equipe. 
Observando os registros dos EEGs, identifica-se forte aumento de Beta no uso do mapa tátil, com cérebro gastando mais energia, estando mais ansiosa e, ao final do segundo percurso, quando chega deste caminho obtido pelo mapa, ela se apresenta mais insegura, mais preocupada, mais tensa. Diferente destes achados, resgata-se que na fase do caminho apreendido por escuta ela se apresenta mais tranquila, a memorização foi mais fácil e ela não apresentou ansiedade nem gasto energético encefálico, chegando no primeiro destino até mais tranquila que na linha de base 1 .

Esta pesquisa está sendo continuada o que justifica a presença neste artigo apenas dos primeiros resultados. Apesar da incipiência do estudo, pode-se inferir que as técnicas e equipamentos apontadas como adequadas na literatura especializada e adotadas neste estudo, tem encontrado resultado favorável quanto ao registro das sensações encefálicas nas primeiras incursões da pesquisa em campo.

\section{Considerações Finais}

Conforme já citado anteriormente, os trabalhos que aplicam as ferramentas, equipamentos e conceitos das neurociências vem sendo conduzidos no Grupo de Pesquisa em Ergonomia Aplicada ao Ambiente Construído da UFPE, onde pesquisas de teses, dissertações, iniciação científica (PIBIC) e tecnológica (PIBITI) são desenvolvidas na busca de relações entre as teorias de base e os resultados de experimentos realizados. Essas pesquisas colaboram no suprimento da lacuna entre teoria e prática identificada por Karakas e Yildiz (2020, p. 245) quando colocam que "o conhecimento neurocientífico pode fornecer dados baseados em evidências e dados objetivos cuja ausência até o momento tem sido uma das maiores deficiências das teorias atuais em suas tentativas para examinar a experiência humana no ambiente construído".

Dos resultados encontrados até o momento pode-se afirmar que há reações encefálicas detectáveis quando da exposição das pessoas a ambientes e situações planejadas nos experimentos relatados. As regiões do encéfalo ativadas pelas ondas de energias do cérebro traduzem sensações, verbalizadas ou não, mas que correspondem aos fatos observados nas pesquisas.

No experimento realizado com os idosos a inserção do EEG na avaliação teve o propósito de identificar se a ativação encefálica de sensação ao vir uma imagem 3D com características desejáveis corresponderia aos resultados verbalizados e identificados durante a visualização dessas imagens. Nesse sentido, os achados apontaram respostas assertivas à essa investigação. Nas verbalizações feitas pelos idosos pode ser percebida a consciência de elementos favoráveis (ou não) necessários ao ambiente de sala para uma condição ideal. Os idosos se preocuparam mais com a funcionalidade, dimensionamento e conforto dos ambientes residenciais de sala do que com a estética espacial e de seus elementos compositivos. Desse modo, entende-se a associação da utilização da técnica de Eletroencefalografia à Realidade Virtual em espaços residenciais de sala com usuários idosos como elemento inovador e com grande potencial para as investigações do ambiente construído, de uma forma geral, permitindo novas concepções mais adequadas do ponto de vista ergonômico.

$\mathrm{Na}$ condução da pesquisa de trajetos urbanos por pessoas cegas com auxílio de Tecnologias Assistivas, os resultados das gravações de EEG apontam ativações de áreas cerebrais por frequencias que indicam reações de tranquilidade, atenção e ansiedade, perfeitamente associáveis ao momentos e situações vivenciadas.

Embora ainda contando com poucos conclusões, os trabalhos já desenvolvidos indicam resultados promissores e a abertura de um leque de possibilidades de novas pesquisas com caráter de ineditismo de alta relevância. 


\section{Referências Bibliográficas}

ARBIB, M.A. Why should architects care about neuroscience. In: Architecture \& Neuroscience. The Tapio Wirkkala-Rut Bryk Foundation, p. 42-72, 2013.

ARIAS et al., 2012 ARIAS, P; ROBLES-GARCÍA, V.; SANMARTÍN, G.; FLORES, J.; CUDEIRO, J. Virtual Reality as a Tool for Evaluation of Repetitive Rhythmic Movements in the Elderly and Parkinson's Disease Patients. PLoS ONE 7(1): e30021, 2012. Doi: 10.1371/journal. pone.0030021

BEAR, Mark F. Neurociências: desvendando o sistema nervoso/ Mark F. Bear; Barry W. Connors e Michael A. Paradiso; coord. trad. Jorge Alberto Quillfedt (et al.), 2 ed., Porto Alegre: Artmed, 2002.

BERLYNE, Daniel E. Ends and means of experimental aesthetics. Canadian Journal of Psychology, v. 26, p. 303-325, 1972.

BOUERI FILHO, José Jorge. Projeto e dimensionamento dos espaços de atividades. São Paulo: Estação das Letras e Cores, 2008.

BRAINN - um centro de pesquisas sobre o cérebro. Disponível em: https://www.brainn.org.br/brainn-umcentro-de-pesquisas-sobre-o-cerebro/ Acesso em 10.09.2020.

DE PAIVA, A., Neuroscience for architecture: how building design can influence behaviors and performance. Journal of Civil Engineering and Architecture, 2018.

EVANS, Natan; BLANKE, Olaf. Shared electrophysiology mechanisms of body ownership and motor imagery. NeuroImage, v. 64, p. 216-228, 1 January 2013.

FECHINE, Basílio R. A.; TROMPIERI, Nicolino. O processo de envelhecimento: as principais alterações que acontecem com o idoso com o passar dos anos. Inter Sciense Place, Ed.20, v. 1, art. no 7, Janeiro/Março, 2012.

FERNÁNDEZ-PORTERO, Cristina; ALARCÓN, David \& PADURA, Ángela. Dwelling conditions and life satisfaction of older people through residential satisfaction. Journal of Environmental Psychology. Volume 49, p. 1-7, April 2017.

HAM, Tao Y.; GUERIN, Denise A. \& SCOTT, Suzanne C. A cross-cultural comparison of preference for visual attributes in interior environments: America and China. Journal of Interior Design. V. 30, nº 2, p. 37$50,2004$.

IBGE - Instituto Brasileiro de Geografia e Estatística. PNAD - Pesquisa Nacional por Amostra de Domicílios 2016: população idosa cresce 16,0\% frente a 2012 e chega a 29,6 milhões. 2017. Disponível em: https://agenciadenoticias.ibge.gov.br/agencia-noticias/2013-agencia-de-noticias/releases/18263-pnad2016-populacao-idosa-cresce-16-0-frente-a-2012-e-chega-a-29-6-milhoes.html. Acesso em: 13 dezembro 2017.

JOHNSON, Angie. Visualisation techniques, human perception and the built environment. Northumbria Working Paper Series: Interdisciplinary Studies in the Built and Virtual Environment, v. 2 (2), p. 93-103, 2009.

KAPLAN, Stephen. Perception and landscape: conceptions and misconceptions. In: NASAR, Jack L. (Ed) Environmental aesthetics: theory, research and applications. New York: Cambridge University Press, p. 45$55,1988$. 
KARAKAS, Tulay; YILDIZ, Dilek. Exploring the influence of the built environment on human experience through a neuroscience approach: A systematic review. Frontiers of Architectural Research, v. 9, Issue 1, p. 236-247, 2020. https://doi.org/10.1016/j.foar.2019.10.005.

KIMER, Cláudio; KIMER, Tereza G. Evolução e Tendências da Realidade Virtual e da Realidade Aumentada. In: RIBERIO, Marcos W. S.; ZORZAL, Ezequiel R. (Orgs). Realidade Virtual e Aumentada: Aplicações e Tendências. Editora SBC - Sociedade Brasileira de Computação: Uberlândia - MG, p. 10-25, 2011.

MONT'ALVÃO, Cláudia. A ergonomia do ambiente construído no Brasil. In: MONT'ALVÃO, Cláudia; VILLAROUCO, Vilma. (Orgs). Um novo olhar para o projeto: a ergonomia no ambiente construído.

Editora 2AB: Teresópolis, RJ, p. 13-24, 2011.

MUSSATTO, Greice G.; AVILA e SILVA, Scheila. Perspectivas e Potencialidades da Interface CérebroMáquina. Revista de Sistemas de Informação da FSMA, n.13, p. 51-56, 2014.

NAHAS, T. R. Nova perspectiva para tratamento de distúrbios atencionais. Vox scientiae, a. 1, n. 2, maio/ jun. 2001.

NASAR, Jack L. Visual Quality by Design. Holland MI: American Society of Interior Designers, Haworth Inc. United States of America, 2008.

NERI, Anita Liberalesso. Palavras-chave em gerontologia. 3. ed. Campinas-SP: Editora Alínea, 2008.

PARASURAMAN, Raja \& RIZZO, Matthew. Introduction to Neuroergonomics. In: PARASURAMAN, Raja \& RIZZO, Matthew (Ed.). Neuroergonomics: The Brain at Work. New York: Oxford University Press, Inc, p. 3-11, 2007.

PFURTSCHELLER, Gert. Special Issue: Brain-Computer Interface (BCI) Systems in Virtual Reality Environments Guest Editor's Introduction. 2010.

SANOFF, Henry. Visual research methods in design. New York: Van Nostrand Reinhold, 1991. SCHERER, Reinhold; LEE, Felix; SCHLÖG, Alois; LEEB, Robert; BISCHOF, Horst; PFURTSCHELLER, Gert. Toward Self-Paced Brain-Computer Communication: Navigation Through Virtual Worlds. IEEE Transactions on Biomedical Engineering, Vol. 55, No. 2, February 2008.

TUAN, Yi-Fu. Espaço e lugar: a perspectiva da experiência. Tradução: Lívia de Oliveira. Londrina: Eduel, 2013.

UN-ESA. United Nations, Department of Economic and Social Affairs, Population Division. World Population Prospects: The 2017 Revision, Key Findings and Advance Tables. Working Paper No. $\mathrm{ESA} / \mathrm{P} / \mathrm{WP} / 248,2017$.

VASQUEZ, Melissa Marin; MATTOS, Liara Mucio De; BERTOLACCINI, Guilherme Da Silva; LANDIM, Paula Da Cruz; PASCHOARELLI, Luís Carlos; MEDOLA, Fausto Orsi; "Neurociência e Ciências Sociais: uma Revisão dos Conceitos do Neuromarketing, da Neuroergonomia e do Neurodesign", p. 5283-5292. In: Anais do $12^{\circ}$ Congresso Brasileiro de Pesquisa e Desenvolvimento em Design [= Blucher Design Proceedings, v. 9, n. 2]. São Paulo: Blucher, 2016. ISSN 2318-6968, DOI 10.5151/despro-ped2016-0452

VAUGHN, Adel C. Aesthetics and Performance Evaluation of Post-Industrial Public Parks. Landscape Architecture Undergraduate Honors Theses, v. 6, 2015. 
VILLAROUCO, Vilma; SANTIAGO, Zilsa; NASCIMENTO, Paulo; MEDEIROS, Raquel. Ergonomia, Neurociência E Acessibilidade, In:Mont'Alvão, Cláudia/Villarouco, Vilma (Orgs), Um novo olhar para o projeto 5. Rio de Janeiro, 2AB, 2020.

ZEISEL, John. Inquiry by design: environment/behavior/neuroscience in archtecture, interiors, landscape, and planning. New York: W. W. Norton; Revised edition, 2006.

WILSON, J. R. Fundamentals of Ergonomics in theory and practice. Applied Ergonomics, v. 31, p. 557-567, 2000.

\section{Agradecimentos}

Agradecemos à Universidade Federal do Ceará pela Bolsa PIBITI-UFC concedida ao projeto e à Ronaldo Academy que cedeu suas instalações para realização de parte da pesquisa. 